\section{Feeling fine with prime interdental brushes}

Help patients avoid the risk of oral diseases with some of the finest interdental brushes on the market, according to leading oral healthcare specialist, Curaprox, which is offering the CPS Prime range.
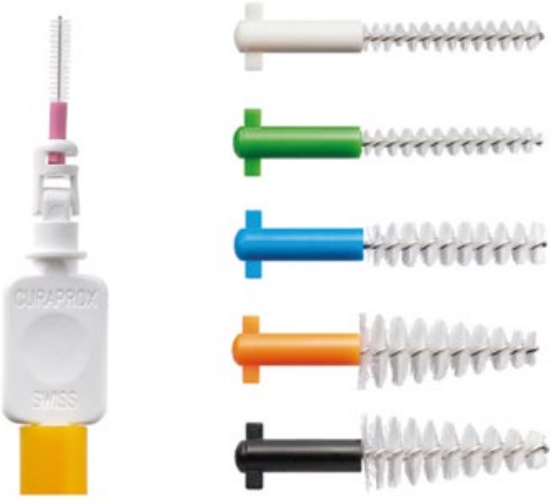

The high quality of these products including Prime Plus and Prime Handy - ensure that one movement in and out between each tooth is all it takes for safe and effective cleaning.

This is thanks to the conical design of CPS Prime brushes, which feature nickel-free, CURAL surgical wires that can clean the smallest of interdental spaces without risk of injury.

More information is available by calling 01480 862084, emailing info@curaprox.co.uk or visiting www.curaprox.co.uk.

\title{
Course for comprehensive occlusion, clinical records and bite splints
}

A comprehensive four day hands-on course to give delegates a thorough and clinically relevant understanding of occlusion is due to take place on 7 to 10 May 2019, organised by Mizrahi Dental Teaching.

The course will be given by Dr Basil Mizrahi and Dr Jurgita Sybaite.

Rather than focus on specific philosophies and concepts, it will start off with the basics such as occlusal contacts and tooth morphology and build up to more complex aspects such as mandibular movement and occlusal adjustment.

Practical exercises will make use of giant tooth models and drawings. To complete the topic, delegates will be taught about occlusal splints and their therapeutic principles.

Differences and use in clinical practice will be discussed in detail. Each delegate will have the opportunity to fit and adjust a full upper bite splint. Upon completion, delegates will develop a clear understanding on practical application of occlusal principles.

The course runs from 7 to 10 May 2019 in central London.

For more information on this and other upcoming courses, contact Mizrahi Dental Teaching by email at info@mizrahi-dental-teaching.co.uk, visit www.mizrahi-dental-teaching.co.uk or call 02033942984.

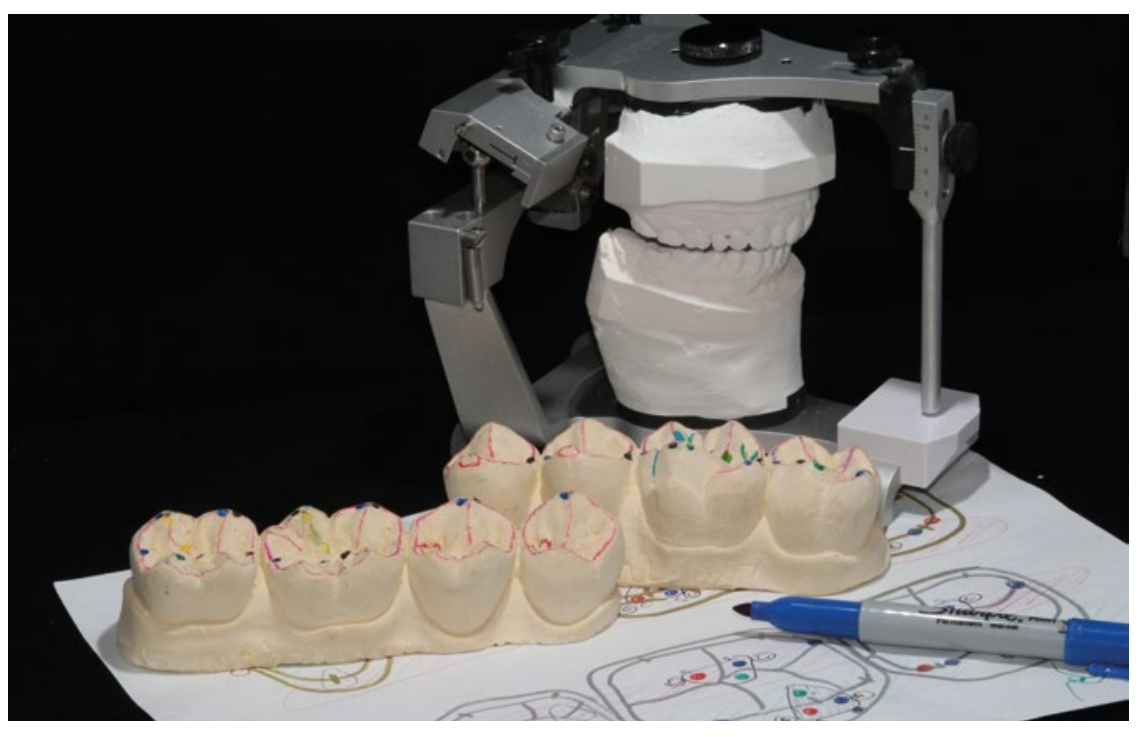

\section{Benefits for all}

The British Society of Dental Hygiene and Therapy (BSDHT) offers its members an array of benefits. Regardless of their interests, their experience level or location, there is something for all.

Through the website, members have convenient access to the latest updates on

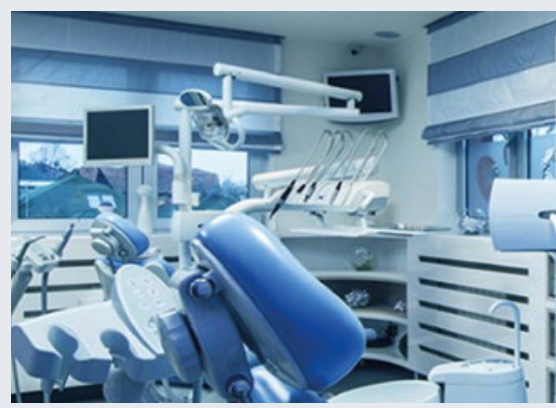

regulation, research papers and guidance notes on key issues.

BSDHT Regional Meetings are also held across the country to help individuals develop their knowledge and skills in a wide range of topics.

These are presented by leading lights in the

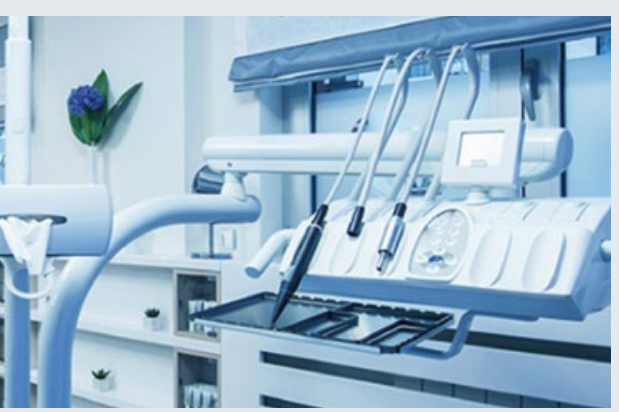

field, who are keen to share their experience and encourage others to continue raising the standard of dental hygiene and therapy provided to patients.

Another key advantage of joining the BSDHT is the discounted rate for the annual Oral Health Conference, which this year will be held at the ICC Wales in Newport, 22 and 23 November 2019.

With up to 12 hours of enhanced CPD available, plus the chance to get up-to-date with the very latest concepts, technologies and products in the profession, this is one event not to miss.

More information is available by visiting www.bsdht.org.uk, calling 01788575050 or emailing enquiries@bsdht.org.uk. 